\title{
Treatment of osteoporosis: recognizing and managing cutaneous adverse reactions and drug-induced hypersensitivity
}

\author{
P. Musette • M. L. Brandi • P. Cacoub • J. M. Kaufman • \\ R. Rizzoli • J.-Y. Reginster
}

Received: 28 July 2009 / Accepted: 12 October 2009 / Published online: 17 November 2009

(C) International Osteoporosis Foundation and National Osteoporosis Foundation 2009

\begin{abstract}
Summary Cutaneous adverse reactions are reported for many treatments including antiosteoporotic agents. This position paper includes an algorithm for their recognition. With early recognition and proper management, including immediate and permanent withdrawal of the culprit agent, accompanied by hospitalization, rehydration, and systemic corticosteroids, if necessary, the prognosis is good.

Introduction Cutaneous adverse reactions are reported for many therapeutic agents and observed in between $0 \%$ and $8 \%$ of treated patients depending on the drug. The
\end{abstract}

P. Musette

Department of Dermatology and INSERM Unit 905,

Charles Nicolle University Hospital,

Rouen, France

M. L. Brandi

Department of Internal Medicine, University of Florence,

Florence, Italy

P. Cacoub

Department of Internal Medicine, AH-HP, Hôpital Pitié

Salpétrière, and Université Pierre et Marie Curie,

Paris 6,

Paris, France

J. M. Kaufman

UZ Gent Department of Internal Medicine,

Ghent, Belgium

R. Rizzoli

Geneva University Hospitals,

Geneva, Switzerland

J.-Y. Reginster $(\bowtie)$

Department of Public Health Sciences, University of Liège,

Liège, Belgium

e-mail: jyreginster@ulg.ac.be antiosteoporotic agents are reputed to be safe in terms of cutaneous effects; however, there have been a number of case reports of cutaneous adverse reactions, which merit consideration. This was the subject of a Working Group meeting of the European Society for Clinical and Economic Aspects of Osteoporosis and Osteoarthritis in April 2009, to focus on the impact of cutaneous adverse reactions and drug-induced hypersensitivity in the management of postmenopausal osteoporosis. We prepared this position paper following these discussions, and include an algorithm for their recognition.

Methods We reviewed cutaneous adverse reactions observed with antiosteoporotic agents, including information from case reports, regulatory documents, and pharmacovigilance.

Results The cutaneous adverse reactions range from benign reactions including exanthematous or maculopapular eruption (drug rash), photosensitivity, and urticaria to the severe and potentially life-threatening reactions, angioedema, drug rash with eosinophilia and systemic symptoms (DRESS), Stevens Johnson syndrome (SJS), and toxic epidermal necrolysis (TEN). Review of available evidence shows that cutaneous adverse reactions occur with all commonly used antiosteoporotic agents. Notably, there are reports of SJS and TEN for bisphosphonates, and of DRESS and TEN for strontium ranelate. These severe reactions remain very rare $(<1$ in 10,000 cases).

Conclusion With early recognition and proper management, including immediate and permanent withdrawal of the culprit agent, accompanied by hospitalization and rehydration and systemic corticosteroids if necessary, the prognosis is good.

Keywords Anti-osteoporotic treatments · Cutaneous adverse reactions $\cdot$ Hypersensitivity reactions · Osteoporosis 


\section{Introduction}

An adverse drug reaction is generally defined as any reaction resulting from an intervention related to the use of a medicinal product [1]. Such reactions are frequent and can reach many organs. The skin is a common site for adverse drug reactions, and current estimates are that $2.2 \%$ of all hospitalized patients have cutaneous adverse reactions to their treatment [2]. Most are due to drug-induced hypersensitivity, i.e., activation of an unexpected and exaggerated immune response, and clinically resemble an allergic reaction or viral disease. Cutaneous adverse reactions are reported for a wide range of therapeutic agents, and are observed in between $0 \%$ and $8 \%$ of patients for most drugs, with the highest rates reported for antibiotics $(1 \%$ to $8 \%)$ and nonsteroidal anti-inflammatory drugs (NSAIDs; $(0.3 \%$ to $0.7 \%)[2,3]$.

Antiosteoporotic agents are reputed to be safe in terms of cutaneous effects. However, there has been case reports in the literature of a variety of cutaneous adverse reactions associated with antiosteoporotic agents and most recently reported with strontium ranelate. Because of the rarity of these events, the situation for cutaneous adverse reactions with antiosteoporotic agents has never been reviewed. On April 1, 2009, the European Society for Clinical and Economic Aspects of Osteoporosis and Osteoarthritis organized a Working Group meeting to focus on the impact of cutaneous adverse reactions and drug-induced hypersensitivity in the management of postmenopausal osteoporosis. We have prepared this article following these discussions. We aim to describe the recognition and management of cutaneous adverse reactions and drug-induced hypersensitivity and review current knowledge on antiosteoporotic agents in clinical use. This should help facilitate the early recognition and appropriate management of any such cases occurring with antiosteoporotic agents.

\section{Methods}

Relevant articles, authorative reviews, and case reports were identified through a PubMed/MEDLINE search of English-language articles published between 1996 and February 2009. The search strategy included the terms osteoporosis, pharmacovigilance, dermatology, cutaneous adverse reaction, hypersensitivity, rash, eruption, urticaria, photosensitivity, drug rash with eosinophilia and systemic symptoms (DRESS), Stevens Johnson, TEN, bisphosphonate, alendronate, risedronate, ibandronate, zoledronic acid, raloxifene, strontium ranelate, teriparatide, and parathyroid hormone. Separate subsearches were also performed using the above terms and a filter of case reports, as well as a cross-search using the above terms combined. Overall, 646 articles were detected, 17 of which described case reports of cutaneous adverse reactions to antiosteoporotic agents, which were selected by the authors for inclusion in this review. Event rates have been determined from the current European or American regulatory files, as well as postmarketing data collected from the Pharmapendium ${ }^{\mathrm{TM}}$ website for the more severe events [4]. The Pharmapendium database is principally supplied with data from the Food and Drug Administration (FDA) Approval Package Database and Adverse Event Reporting System (ARES; last update January 2009), but also includes information from other sources, notably the European Medicines Agency European Public Assessment Report database.

\section{Recognizing drug-induced cutaneous adverse reactions}

Cutaneous adverse reactions are observed throughout the whole therapeutic armamentarium. There are a number of factors that may predict an adverse reaction or drug-induced hypersensitivity. As regards drug-related aspects, high molecular weight $(>1,000 \mathrm{Da})$, cytotoxicity, and direct binding to immune receptors, such as $\mathrm{T}$ cell receptors, and major histocompatibility complex may all increase the risk for an immunogenic or allergenic response [5]. Other risk factors are related to patient profile, for example, adverse drug reactions appear to be more common in women than in men and in certain ethnic groups. Genetic predisposition to severe drug-induced hypersensitivity to allopurinol or carbamazepine has been described in Han Chinese carrying certain genetic markers for human leukocyte antigen (HLA) $[6,7]$, suggesting a possible route to testing for such reactions. In this context, a randomized trial has indicated that screening patients with human immunodeficiency virus (HIV) for the presence of an HLA allele known to be associated with hypersensitivity to acabavir can reduce the risk of an adverse reaction [8].

Infections, particularly viral infections, also considerably increase the risk for an allergic response to drugs. Pathogenic links between drug-induced hypersensitivity and a range viruses have been postulated, including the herpes simplex virus HHV-6, Epstein-Barr virus, cytomegalovirus, HIV, influenza, and viral hepatitis $[5,9,10]$. The presence of connective tissue disease or autoimmune disease has also been suggested to increase risk.

The rarity of these reactions and the overlap between syndromes makes them difficult to diagnose outside the dermatology clinic. Beyond the clinical presentation, better knowledge of culprit agents and of the delay to onset after treatment initiation can help differential diagnosis. Table 1 summarizes selected cutaneous adverse reactions [11-14]. The cutaneous and systemic symptoms, the delay to onset, and the results of laboratory tests help determine causality. 


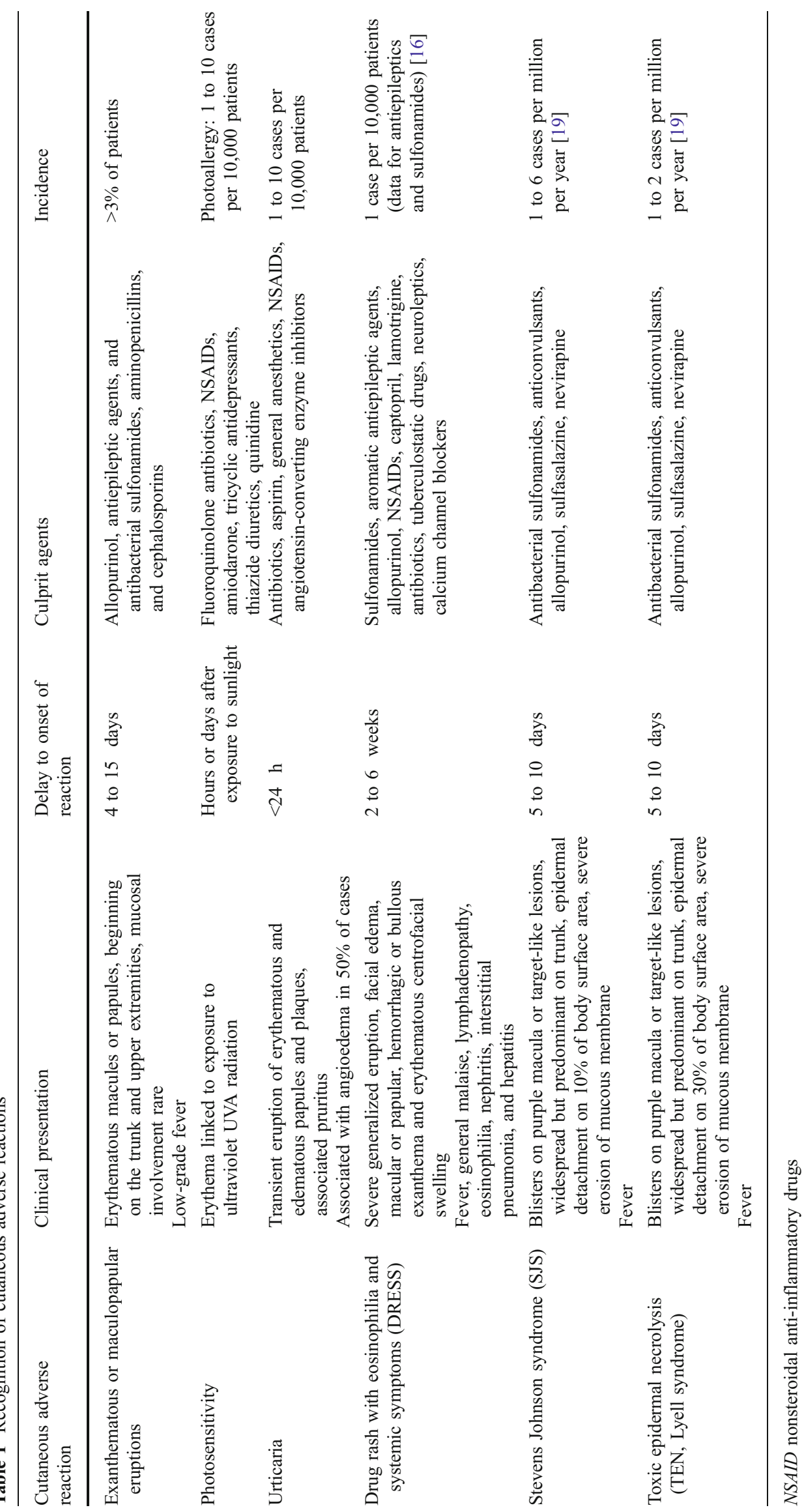


The list includes the benign reactions of exanthematous or maculopapular eruptions (drug rash), photosensitivity, urticaria, and as well as the more severe cutaneous adverse reactions of angioedema, DRESS, Stevens Johnson syndrome (SJS), and toxic epidermal necrolysis (TEN), otherwise known as Lyell syndrome, all of which are potentially lifethreatening (Fig. 1). Our review does not cover cutaneous adverse reactions that have never been reported for antiosteoporotic agents, such as acute generalized exanthematous pustulosis, anaphylactic shock, and fixed drug eruptions. For information on those reactions, the reader is referred to a number of exhaustive reviews on the topic $[11,13]$.

\section{Exanthematous or maculopapular eruption}

The most common cutaneous adverse reaction is an exanthematous or maculopapular eruption, often described more simply as a "drug rash" or a "drug eruption".

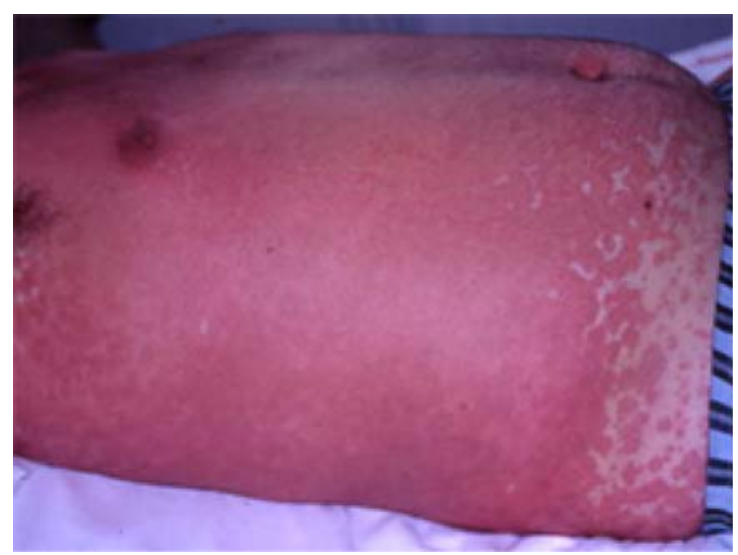

A. Exanthematous or maculopapular eruption

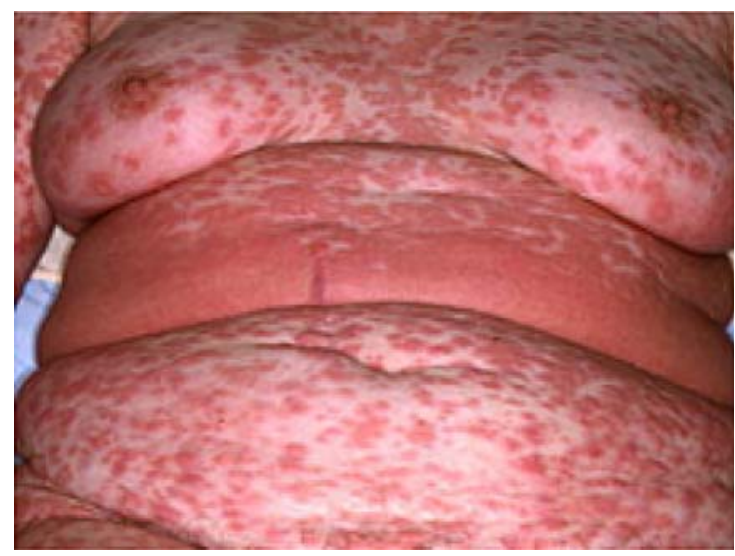

C. DRESS

Fig. 1 Severe cutaneous adverse reactions: a exanthematous or maculopapular eruptions, b urticaria, $\mathbf{c}$ drug rash with eosinophilia and systemic symptoms (DRESS), and d Stevens Johnson syndrome/ toxic epidermal necrolysis. Reproduced with permission from:
Clinically, it begins as erythematous macules or papules on the trunk and upper extremities (Fig. 1a), which progressively become confluent and spread symmetrically downward. Typically, the eruption is polymorphous, though it may be associated with morbilliform, urticarial, or purpuric lesions. Mucosal involvement is rare. The eruption may be accompanied by a low-grade fever.

This benign rash accounts for $>90 \%$ of all cutaneous adverse reactions [2], and generally requires little more than drug withdrawal and symptomatic treatment. The delay to onset of reaction is between 4 to 15 days after treatment initiation, though it may appear 2 days after treatment cessation (the so-called "9th day" eruption). Exanthematous or maculopapular eruptions have been reported for most drugs, with a rate of about $1 \%$ of users. Higher rates $(>3 \%$ of users) have been reported for the antiurolithic agent, allopurinol, antiepileptic agents, and antibacterial sulfonamides, aminopenicillins, and cephalosporins.

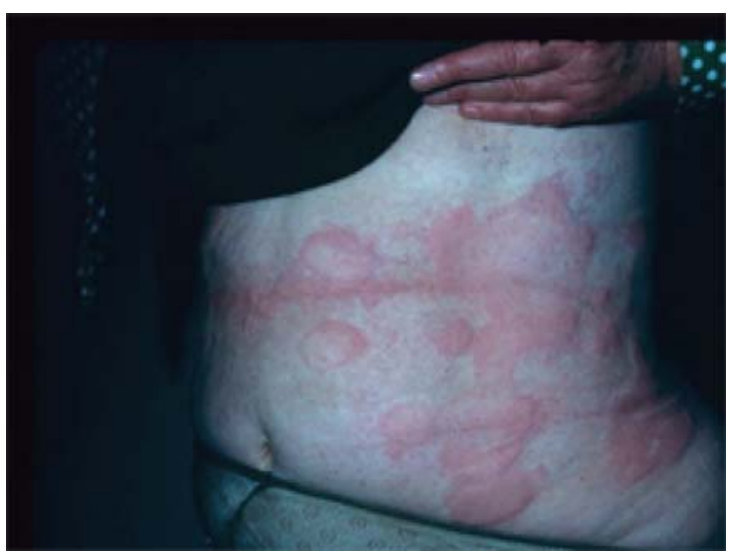

B. Urticaria

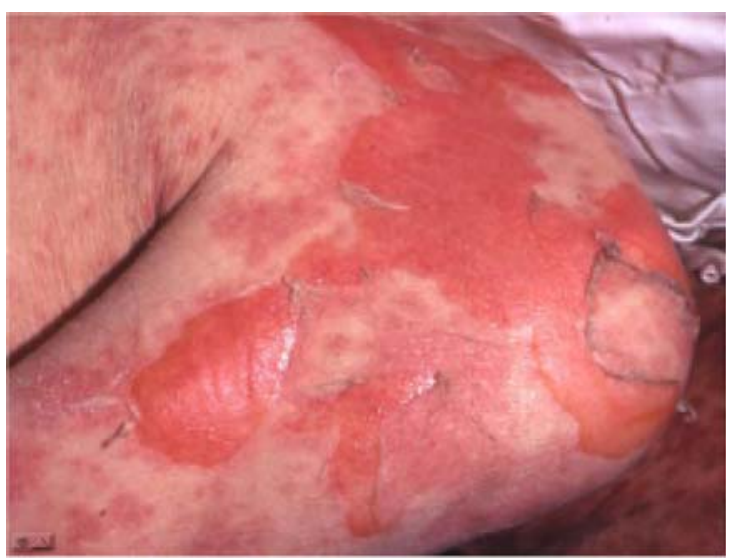

D. Stevens Johnson syndrome/ toxic epidermal necrolysis

Toxidermie ou Réaction Médicamenteuses Graves. Available at: www3.chu-rouen.fr/internet/professionnelSante/infos_medicales/ toxidermie/ Accessed 24 February 2009 


\section{Photosensitivity}

Drug-induced photosensitivity is the occurrence of an erythema, or an exaggerated sunburn, a few hours or days after exposure to sunlight in a treated patient [12, 14, 15]. Individual response is dictated by dose and variations in absorption and metabolism, and also by skin phenotype, with fair-skinned people being the most susceptible. Photosensitivity reactions have been reported for a large number of agents, including fluoroquinolone antibiotics, NSAIDs, amiodarone, tricyclic antidepressants, thiazide diuretics, and quinidine. Most drugs associated with photosensitivity reactions absorb in the ultraviolet A region.

Photosensitivity reactions are further divided into phototoxic and photoallergic reactions; they occurred early after sun exposure and are photodistributed $[12,14,15]$. A phototoxic reaction may occur in any individual receiving the culprit agent, and may be reduced by distancing intake from exposure to sunlight, for example, by dosing in the evening, or by reducing sun exposure during treatment. Photoallergic reactions correspond to drug-induced hypersensitivity, and are more typical of delayed-type immune-mediated reactions. The incidence of photoallergy is generally rare (one to ten cases per 10,000). It is more likely to be eczematous and pruritic in nature. It is usually transient, but may persist in rare cases for months or years.

\section{Urticaria and angioedema}

Urticaria consists of a transient eruption of itchy erythematous and edematous papules and plaques (Fig. 1b), which is often associated with pruritus [11, 14]. The reaction is termed angioedema when it involves dermal and subcutaneous tissues. More severe cases may include angioedema of the buccal mucosa, tongue, larynx, and pharynx, and possibly other systems leading to anaphylactic shock. In about $50 \%$ of cases, urticaria is associated with angioedema. The eruption may occur anywhere on the body; fever may occur in cases with extensive facial angioedema.

Drug-induced urticaria and angioedema usually appear within $24 \mathrm{~h}$ of intake. One strong feature of these reactions is the waxing and waning over a day: the reaction may last for a few hours and then disappear within $24 \mathrm{~h}$ without leaving any scarring. They generally resolve spontaneously and completely upon withdrawal of the culprit drug. Urticaria is a common reaction to many drugs, and is associated, for example, with antibiotics, aspirin, and general anesthetics. NSAIDs and angiotensin-converting enzyme (ACE) inhibitors are known to produce combined urticaria and angioedema. The incidence of these reactions remains low, at around one case per 10,000 , with slightly higher rates for ACE inhibitors (two to ten cases per 10,000).

Drug rash with eosinophilia and systemic symptoms

The DRESS syndrome, also known as "drug hypersensitivity syndrome" or "drug-induced hypersensitivity syndrome" was first described in 1939, a year after the introduction of phenytoin [16]. The DRESS syndrome includes a severe cutaneous eruption (Fig. 1c), as well as lymph node enlargement, fever, and systemic involvement, such as hepatitis, interstitial nephritis, interstitial pneumonia, and hematological abnormalities [14, 16-18]. The multisystem involvement, including visceral tissue, differentiates DRESS clinically from a simple drug rash.

The cutaneous reaction begins as a macular erythema, progressing into asymmetrical, red, pruritic, confluent, papular eruption, possibly with pustules. Mucosal involvement may be present and facial edema is frequent. The eruption begins on the upper truck and face and descends to the lower extremities. Clinically, the patient presents with general malaise and a high and spiking fever $\left(>38.5^{\circ} \mathrm{C}\right)$ [16], though tissue culture is negative for underlying infection. In terms of visceral tissue, the kidney and liver are involved, with varying degrees of hepatitis in $60 \%$ of cases. Lymphadenopathy is also frequent, due to lymphoid hyperplasia. More rarely, the brain, heart, lungs, and thyroid may be implicated. The predominant biological finding is hypereosinophilia ( $70 \%$ of cases).

One distinguishing feature of the DRESS syndrome is the delay to onset, which occurs between 2 to 6 weeks after treatment initiation. The rate of mortality is generally reported to be between $8 \%$ and $10 \%$. Prompt drug withdrawal and appropriate well-informed management, including rapid initiation of systemic corticosteroids, can lead to an improvement in the prognosis. Agents known to provoke a DRESS syndrome include sulfonamides, aromatic antiepileptic agents (e.g., phenytoin and phenobarbital), allopurinol, NSAIDs, captopril, lamotrigine, antibiotics, tuberculostatic drugs, neuroleptics, and calcium channel blockers. The factors implicated in the severity of DRESS remain unclear, though the presence of HHV-6 infection may aggravate the prognosis with regard to visceral involvement [10]. The incidence of DRESS is estimated at between one to ten cases per 10,000 for antiepileptic agents and sulfonamides [14, 16].

Stevens Johnson syndrome and toxic epidermal necrolysis

SJS and TEN are the most severe cutaneous adverse reactions $[11,14,16]$. The eruption begins as small blisters on purple maculae and target-like lesions, predominantly on the trunk and rapidly extending to the rest of the body, including severe erosion of the mucous membrane. Con- 
fluence of the necrotic lesions leads to extensive erythema and epidermal detachment (Fig. 1d). The extent of the epidermal detachment determines the actual diagnosis, with SJS showing epidermal detachment on $<10 \%$ of the body surface. TEN is more severe than SJS, with the same lesions, but leading to epidermal detachment on $>30 \%$ of the body surface (intermediate cases of $10 \%$ to $30 \%$ are defined as SJS-TEN overlap) [11, 19]. Fever precedes the cutaneous and mucosal eruption by 24 to $48 \mathrm{~h}$. Systemic involvement includes mild elevation of liver enzymes, as well as pulmonary and intestinal manifestations, with detachment of epithelia similar to the cutaneous effects leading to respiratory distress and diarrhea. In the case of pulmonary involvement, the prognosis may be very poor.

The delay to onset of SJS and TEN is generally 5 to 10 days after treatment initiation. The rate of mortality depends on the severity of the lesions, and is currently reported to be about $10 \%$ for SJS and $>30 \%$ for TEN [14], mainly due to respiratory failure or sepsis. Mortality can be reduced by rapid recognition and an effective management strategy. SJS and TEN are extremely rare, with an estimated incidence of one to six cases per million per year, about $70 \%$ of which are linked to adverse drug reactions. Drugs associated with higher risk of SJS and TEN [20] include antibacterial sulfonamides, antiepileptic agents, allopurinol, sulfasalazine, and the antiretroviral agent nevirapine.

\section{Management of cutaneous adverse reactions}

Management strategies depend on the type and severity of the reaction [13] but should always remain on the side of caution. In Fig. 2, we present a decision algorithm for the physician faced with a cutaneous eruption in a patient receiving a new treatment. The most important action is to immediately withdraw the culprit agent and refer for specialist care if necessary.

The more benign cutaneous adverse reactions of exanthematous or maculopapular eruption (drug rash), photosensitivity, urticaria, and angioedema may only require monitoring and symptomatic treatment (emollients). More severe forms of these benign eruptions may require systemic antihistamines and topical corticosteroids and intravenous adrenaline in the most severe cases of angioedema bordering on anaphylactic shock. Rechallenge should be avoided.

In cases of severe cutaneous adverse reaction, immediate and permanent withdrawal of the culprit agent is essential. The DRESS syndrome requires systemic corticosteroid therapy $(0.5-1 \mathrm{mg} / \mathrm{kg})$ in cases of visceral involvement $[16,18,21]$. Regular monitoring is particularly important, and appropriate management should be instigated in case of liver, pulmonary, or kidney failure. TEN and SJS require specialist care due to the epidermal detachment, with procedures paralleling those applied in the burns unit $[16$,

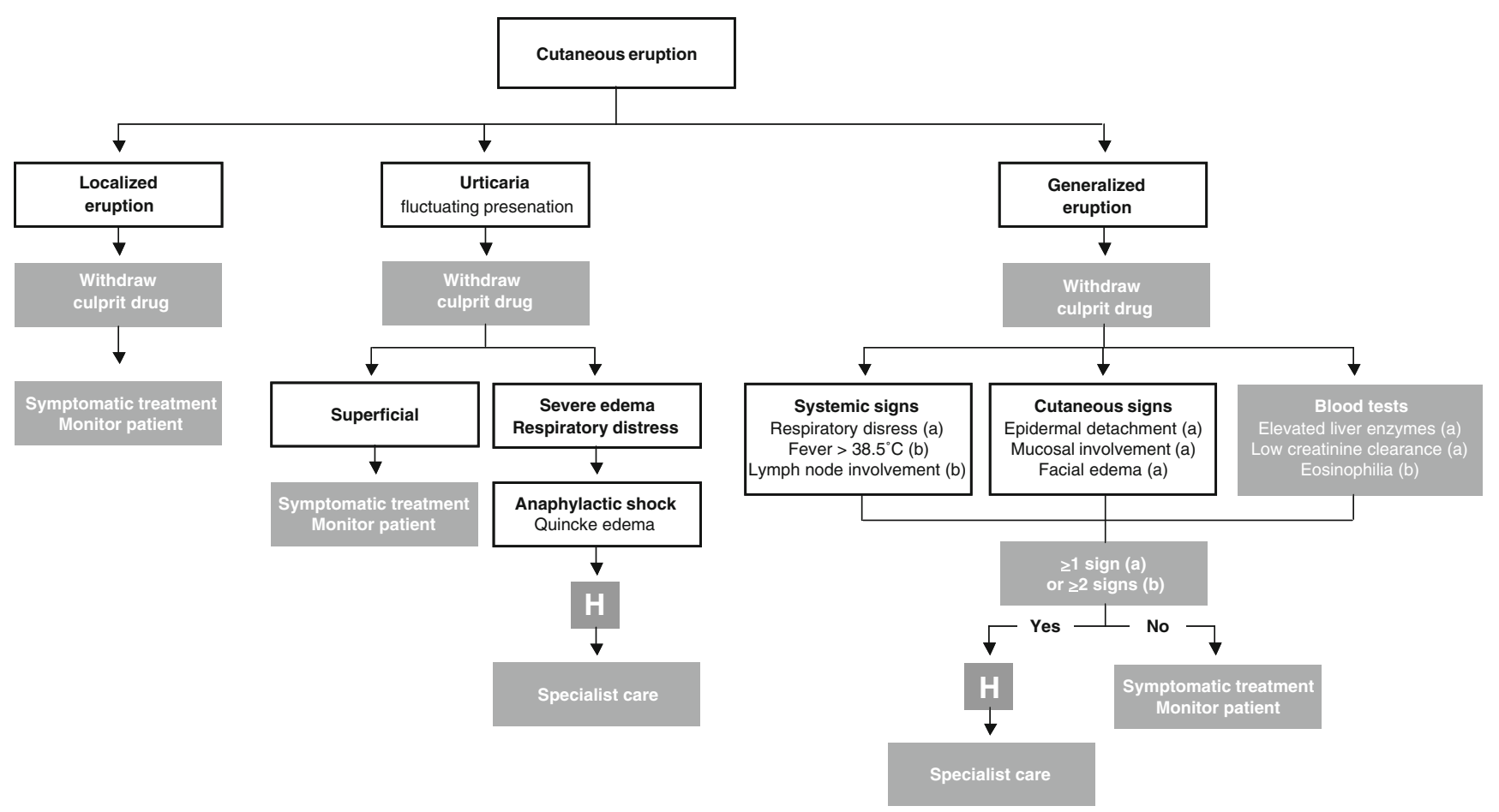

Fig. 2 Decision algorithm in the event of a cutaneous eruption in a patient receiving a newly prescribed treatment. *Immediate referral to hospital if present 
21]. Systemic corticosteroids and intravenous immunoglobulins have been tried in SJS, but their use in TEN remains controversial and not recommended in the absence of randomized trial evidence [22].

The potential of intravenous immunoglobulins and other experimental treatments in the management of severe cutaneous adverse reactions is currently under investigation. On the basis of a hypothesis of an intimate relationship between reactivation of herpes virus and the onset of a hypersensitivity syndrome, DRESS patients have been successfully treated with pulsed intravenous immunoglobulin $\mathrm{G}$ (IgG) in a small-scale study [23]. Some authors have also found promising results with intravenous IgG in TEN patients [24], but other series were inconclusive. There is not enough evidence to support the use of $\operatorname{IgG}$ as part of the management strategy for these patients $[22,25]$.

\section{Cutaneous adverse reactions to antiosteoporotic agents}

Although rare, recent case reports of cutaneous adverse reactions to antiosteoporotic agents underline the importance of their recognition by practitioners treating postmenopausal osteoporosis. In Table 2, we summarize the cutaneous adverse reactions that have been reported or associated with currently available antiosteoporotic agents.

The bisphosphonates as a class are associated with a range of benign and severe cutaneous adverse reactions, whatever their mode of administration. European regulatory documents for oral alendronate cite rates of about $0.1-1 \%$ for drug rash, pruritus, and erythema, and between $0.01 \%$ and $0.1 \%$ for urticaria, photosensitivity, and angioedema [26]. This is in line with case reports of urticaria [27, 28], erythema multiforme and angioedema [29], superficial gyrate erythema [30], and maculopapular eruptions [31], which have appeared since the drug became available in the mid-1990s. There is also one report of hypertrophic lichen planus [32], which included an itching rash on the trunk and extremities, combined with livid flat papules and hypertrophic prurigo-like papules, but no mucosal involvement. Alendronate is also associated with more severe cutaneous adverse reactions, with cases of SJS and TEN, though these remain very rare $(<1$ case per 10,000 users) [26]. Alendronate has been in clinical use since 1993, and since that time there have been 19 cases of SJS and 15 cases of TEN reported to the FDA ARES database [4].

The other commonly used oral bisphosphonate, risedronate, has been in clinical use since 1997. Its use is associated with a similar range of cutaneous adverse

Table 2 Cutaneous adverse reactions associated with antiosteoporotic drugs

\begin{tabular}{|c|c|c|}
\hline Drug & Cutaneous adverse reactions reported & Frequency \\
\hline \multirow[t]{3}{*}{ Alendronate [26] } & Rash, pruritus, erythema & Uncommon ( 1 to 10 per 1,000$)$ \\
\hline & $\begin{array}{l}\text { Urticaria, angioedema, rash with } \\
\text { photosensitivity }\end{array}$ & Rare $(1$ to 10 per 10,000$)$ \\
\hline & SJS, TEN & Very rare $(<1$ per 10,000$)$ \\
\hline \multirow[t]{3}{*}{ Ibandronate [37] } & $\begin{array}{l}\text { Skin reactions at the injection site } \\
\text { (irritation, pain, and swelling) }\end{array}$ & Uncommon ( 1 to 10 per 1,000$)$ \\
\hline & Angioedema, facial edema, urticaria & Rare $(1$ to 10 per 10,000$)$ \\
\hline & Hypersensitivity reactions & Rare ( 1 to 10 per 10,000$)$ \\
\hline \multirow[t]{4}{*}{ Risedronate [33-35] } & Rash & Uncommon ( 1 to 10 per 1,000$)$ \\
\hline & Pruritus & Rare ( 1 to 10 per 10,000$)$ \\
\hline & $\begin{array}{l}\text { Urticaria, angioedema, bullous reactions, } \\
\text { photosensitivity }\end{array}$ & Very rare $(<1$ per 10,000$)$ \\
\hline & SJS & Very rare $(<1$ per 10,000$)$ \\
\hline \multirow[t]{2}{*}{ Zoledronic acid [38] } & Rash & Uncommon ( 1 to 10 per 1,000$)$ \\
\hline & Redness, swelling and/or pain at infusion site & Rare $(1$ to 10 per 10,000$)$ \\
\hline Raloxifene [47] & Rash & Very rare $(<1$ per 10,000$)$ \\
\hline \multirow[t]{3}{*}{ Strontium ranelate $[40]$} & Dermatitis, eczema & Common ( 1 to 10 per 100$)$ \\
\hline & $\begin{array}{l}\text { Hypersensitivity reactions } \\
\text { (angioedema, pruritus, urticaria) }\end{array}$ & Very rare $(<1$ per 10,000$)$ \\
\hline & DRESS, SJS, TEN & Very rare $(<1$ per 10,000$)$ \\
\hline \multirow{2}{*}{$\begin{array}{l}\text { Parathyroid hormone and its } \\
\text { derivatives }[49,50]\end{array}$} & Sweating, erythema at injection site & Common ( 1 to 10 per 100$)$ \\
\hline & Rash & Rare $(1$ to 10 per 10,000$)$ \\
\hline
\end{tabular}

DRESS drug rash with eosinophilia and systemic symptoms, SJS Stevens Johnson syndrome, TEN toxic epidermal necrolysis 
reactions to alendronate: rash in 3-4\% of cases, and pruritus in $2 \%[33,34]$. This was confirmed in a pharmacovigilance survey in more than 13,000 patients in England, which also reported cases of urticaria and photosensitivity [35]. A case report of drug eruption on the lower limbs 3 weeks after initiation of treatment, including multiple infiltrated purpuric plaques, was diagnosed as cutaneous vasculitis [36]. This case resolved completely upon withdrawal of risedronate, though it did reappear on rechallenge. As regards severe cutaneous adverse reactions, the English pharmacovigilance study cited one case of SJS while in the FDA ARES database, there are five reported cases of SJS with risedronate, as well as two cases of TEN [4].

The intravenous bisphosphonates ibandronate and zoledronic acid are relative newcomers to the class and have been in clinical use since 2005 to 2007. Both agents provoke irritation at injection site, including pain and swelling. The regulatory files state that they are also associated with angioedema, facial swelling or edema, and urticaria for ibandronate (one case per 10,000) [37], and rash, erythema, and pruritus for zoledronic acid (one to ten cases per 1,000) [38]. So far, there is one case report of a pruritic maculopapular rash on the lower extremities with fever $\left(39^{\circ} \mathrm{C}\right)$, which appeared 10 days after administration [39]. The patient was treated with intravenous corticosteroids and oral antihistamines, and the rash and other symptoms subsided within $48 \mathrm{~h}$.

It may be too early in the lifecycle of these two agents to determine the incidence of severe drug hypersensitivity, though this is mentioned in the European regulatory file for ibandronate [37]. The FDA ARES cites one case of SJS with ibandronate, four cases of SJS, and four cases of TEN with zoledronic acid [4].

The European regulatory documents for strontium ranelate cite dermatitis and eczema as common (rates $2.3 \%$ and $1.8 \%$ versus $2.0 \%$ and $1.4 \%$ for placebo), and rash, pruritus, urticaria, and angioedema as very rare $(<1$ case per 10,000) [40]. There is one case report of an erythematous rash with violaceous patches and plaques, which was diagnosed as an interstitial granulomatous reaction [41]. Another case of a generalized cutaneous eruption [42] with no fever with strontium ranelate resolved completely after withdrawal of treatment. Hypersensitivity syndromes, such as DRESS [43, 44] and TEN [45] have also been reported. However, they are very rare $(<1$ case per 10,000), and with early recognition and appropriate management, the prognosis can be improved [40, 46]. Strontium ranelate is not currently available in the United States of America and so the FDA ARES database does not include cases of hypersensitivity reactions, though it does mention two cases of SJS from the European files [4].

The other antiosteoporotic treatments are associated with low rates of cutaneous adverse reactions. Treatment with the selective estrogen receptor modulator raloxifene is associated with rash, flushing, and sweating [47, 48] in line with its mode of action on the estrogen receptors. To our knowledge, there are no case reports of other cutaneous adverse reactions with raloxifene. The use of parathyroid hormone has been linked to erythema at injection site, which is reported in $0.1-1 \%$ of patients $[49,50]$. The anabolic agent teriparatide is associated with rash and increased sweating [49] at a slightly higher frequency (1$10 \%)$. There is no evidence of hypersensitivity reactions with either of these agents. Finally, phase II trials of the human monoclonal antibody denosumab have reported moderately increased rates of rash $(2-11 \%$, according to dosage, versus $0 \%$ in placebo groups) $[51,52]$. Whether these effects are serious remain to be seen when the results of ongoing phase III trials appear.

\section{Discussion and conclusion}

Despite the scarcity of data, review of the evidence available from regulatory documents and case reports shows that cutaneous adverse reactions occur with all commonly used antiosteoporotic agents and are usually benign. In their most severe forms, they are extremely rare, occurring in $<1$ in 10,000 cases. These rates are on a par with agents such as antibiotics and antiepileptics. These cutaneous adverse reactions occur at lower rates, and with lesser severity, than other agents used in rheumatology, e.g., allopurinol, sulfasalazine (for which, notably, there are 27 cases of SJS and 14 cases TEN in the FDA ARES database [4]), and the NSAIDs. The incidence of cutaneous adverse reactions with antiosteoporotic agents should be regarded as a reason for vigilance and action in the case of any unusual cutaneous effect. It is important to weigh the risks involved against the benefits of treatment in terms of prevention of osteoporotic fracture, particularly hip fracture which carries a high risk [53, 54].

Perusal of the case reports indicates more cutaneous adverse reactions with agents that have been in clinical use the longest (e.g., alendronate) and fewer for more recent agents (e.g., zoledronic acid and ibandronate). This may be a simple consequence of the rarity of the events, which mount up as the number of treated patients increase. This illustrates the difficulty of comparing the different treatments, even among those from the same class.

The pathogenesis of these reactions remains unclear. There has been speculation that cutaneous adverse reactions may be due to the culprit drug acting as a hapten or prohapten, or due to some pharmacological interaction with the immune system [55]. Whether this also applies to antiosteoporotic agents remains to be elucidated by further 
research though this may be compromised by the low incidence of these events. With early recognition and proper management, including immediate and permanent withdrawal of all culprit agents, accompanied by hospitalization and rehydration and systemic corticosteroids if necessary, the prognosis is good.

Conflicts of interest Professor P. Musette is a consultant/advisor for Servier.

Professor M-L Brandi has no conflict of interest for this manuscript.

Professor P. Cacoub has disclosed that he has been the recipient of research grants from Schering Plough, Roche, Servier, and Gilead; that he has received honoraria from Roche, Servier, Bristol Myers Squibb, Sanofi Aventis, Gilead, and Schering Plough; and that he is a consultant/advisor to Roche, Servier, Bristol Myers Squibb, Sanofi Aventis, and Gilead Schering Plough.

Doctor J-M Kaufman has no conflict of interest.

Doctor R. Rizzoli has disclosed that he is a consultant/advisor to Merck, Roche, Servier, Danone, Nycomed, Eli Lilly, and Amgen; and that he is on the Speakers' Bureau for Roche, Novartis, Servier, and Amgen.

Professor J-Y Reginster has disclosed that he has been the recipient of research grants from Bristol Myers Squibb, Merck Sharp and Dohme, Rottapharm, Teva, Lilly, Novartis, Roche, GlaxoSmithKline, Amgen, and Servier; that he is a consultant/advisor to Servier, Novartis, Negma, Lilly, Wyeth, Amgen, GlaxoSmithKline, Roche, Merckle, Nycomed, NPS, Theramex, and UCB; and that he has been the recipient of lecture fees for speaking at meetings on behalf of Merck Sharp and Dohme, Lilly, Rottapharm, IBSA, Genevrier, Novartis, Servier, Roche, GlaxoSmithKline, Teijin, Teva, Ebewee Pharma, Zodiac, Analis, Theramex, Nycomed, and NovoNordisk.

\section{References}

1. Edwards IR, Aronson JK (2000) Adverse drug reactions: definitions, diagnosis, and management. Lancet 356:1255-59

2. Hunziker T, Kunzi UP, Braunschweig S, Zehnder D, Hoigne R (1997) Comprehensive hospital drug monitoring (CHDM): adverse skin reactions, a 20-year survey. Allergy 52:388-93

3. Bigby M (2001) Rates of cutaneous reactions to drugs. Arch Dermatol 137:765-70

4. US Food and Drugs Administration (2009) Pharmapendium

5. Gomes ER, Demoly P (2005) Epidemiology of hypersensitivity drug reactions. Curr Opin Allergy Clin Immunol 5:309-16

6. Hung SI, Chung WH, Liou LB, Chu CC, Lin M, Huang HP, Lin YL, Lan JL, Yang LC, Hong HS, Chen MJ, Lai PC, Wu MS, Chu CY, Wang KH, Chen CH, Fann CS, Wu JY, Chen YT (2005) HLA-B*5801 allele as a genetic marker for severe cutaneous adverse reactions caused by allopurinol. Proc Natl Acad Sci U S A 102:4134-39

7. Chung WH, Hung SI, Hong HS, Hsih MS, Yang LC, Ho HC, Wu JY, Chen YT (2004) Medical genetics: a marker for Stevens Johnson syndrome. Nature 428:486

8. Mallal S, Phillips E, Carosi G, Molina JM, Workman C, Tomazic J, Jagel-Guedes E, Rugina S, Kozyrev O, Cid JF, Hay P, Nolan D, Hughes S, Hughes A, Ryan S, Fitch N, Thorborn D, Benbow A (2008) HLA-B*5701 screening for hypersensitivity to abacavir. N Engl J Med 358:568-79

9. Mockenhaupt M (2007) Epidemiology and causes of severe cutaneous adverse reactions to drugs, pp 18-31
10. Eshki M, Allanore L, Musette P, Milpied B, Grange A, Guillaume JC, Chosidow O, Guillot I, Paradis V, Joly P, Crickx B, Ranger-Rogez S, Descamps V (2009) Twelve-year analysis of severe cases of drug reaction with eosinophilia and systemic symptoms: a cause of unpredictable multiorgan failure. Arch Dermatol 145:67-72

11. Roujeau JC (2005) Clinical heterogeneity of drug hypersensitivity. Toxicology 209:123-29

12. Svensson CK, Cowen EW, Gaspari AA (2001) Cutaneous drug reactions. Pharmacol Rev 53:357-79

13. Aberer W, Kranke B (2008) Clinical manifestations and mechanisms of skin reactions after systemic drug administration. Drug Discovery Today 5:e237-e247

14. Valeyrie-Allanore L, Sassolas B, Roujeau JC (2007) Drug-induced skin, nail and hair disorders. Drug Saf 30:1011-30

15. Morison WL (2004) Clinical practice. Photosensitivity. N Engl J Med 350:1111-17

16. Wolf R, Orion E, Marcos B, Matz H (2005) Life-threatening acute adverse cutaneous drug reactions. Clin Dermatol 23:171-81

17. Bocquet H, Bagot M, Roujeau JC (1996) Drug-induced pseudolymphoma and drug hypersensitivity syndrome (drug rash with eosinophilia and systemic symptoms: DRESS). Semin Cutan Med Surg 15:250-257

18. Shiohara T, Takahashi R, Kano Y (2007) Drug-induced hypersensitivity syndrome and viral reactivation, pp. 251-266

19. Borchers AT, Lee JL, Naguwa SM, Cheema GS, Gershwin ME (2008) Stevens-Johnson syndrome and toxic epidermal necrolysis. Autoimmun Rev 7:598-605

20. Mockenhaupt M, Viboud C, Dunant A, Naldi L, Halevy S, Bouwes Bavinck JN, Sidoroff A, Schneck J, Roujeau JC, Flahault A (2008) Stevens-Johnson syndrome and toxic epidermal necrolysis: assessment of medication risks with emphasis on recently marketed drugs. The EuroSCAR-study. J Invest Dermatol 128: 35-44

21. Ghislain PD, Roujeau JC (2002) Treatment of severe drug reactions: Stevens-Johnson syndrome, toxic epidermal necrolysis and hypersensitivity syndrome. Dermatol Online J 8:5

22. Allanore L, Roujeau JC (2007) Clinic and pathogenesis of severe bullous skin reactions: Stevens-Johnson Syndrome, Toxic Epidermal Necrolysis, pp. 267-277

23. Shiohara T, Inaoka M, Kano Y (2006) Drug-induced hypersensitivity syndrome (DIHS): a reaction induced by a complex interplay among herpesviruses and antiviral and antidrug immune responses. Allergol Int 55:1-8

24. Viard I, Wehrli P, Bullani R, Schneider P, Holler N, Salomon D, Hunziker T, Saurat JH, Tschopp J, French LE (1998) Inhibition of toxic epidermal necrolysis by blockade of CD95 with human intravenous immunoglobulin. Science 282:490-493

25. Faye O, Roujeau JC (2005) Treatment of epidermal necrolysis with high-dose intravenous immunoglobulins (IV Ig): clinical experience to date. Drugs 65:2085-90

26. European Medicines Agency (2008) Alendronate. Summary of product characteristics

27. Kimura M, Kawada A, Murayama Y, Murayama M (2003) Drug eruption due to alendronate sodium hydrate. Contact Dermatitis 48:116

28. Kontoleon P, Ilias I, Stavropoulos PG, Papapetrou PD (2000) Urticaria after administration of alendronate. Acta Derm Venereol 80:398

29. Biswas PN, Wilton LV, Shakir SA (2003) Pharmacovigilance study of alendronate in England. Osteoporos Int 14:507-14

30. High WA, Cohen JB, Wetherington W, Cockerell CJ (2003) Superficial gyrate erythema as a cutaneous reaction to alendronate for osteoporosis. J Am Acad Dermatol 48:945-46

31. Brinkmeier T, Kugler K, Lepoittevin JP, Frosch PJ (2007) Adverse cutaneous drug reaction to alendronate. Contact Dermatitis 57:123-25 
32. Lazarov A, Moss K, Plosk N, Cordoba M, Baitelman L (2002) Alendronate-induced lichen planus. Isr Med Assoc J 4:389-90

33. US Food and Drugs Administration (2002) Risedronate. Description 34. (2009) Vidal 2009. Le Dictionnaire, 85th ed

35. Barrera BA, Wilton L, Harris S, Shakir SA (2005) Prescriptionevent monitoring study on 13, 164 patients prescribed risedronate in primary care in England. Osteoporos Int 16:1989-98

36. Belhadjali H, Slim R, Aouam K, Youssef M, Zili J (2008) Cutaneous vasculitis induced by risedronate. Allergy 63:1405

37. European Medicines Agency (2007) Ibandronate. Summary of product characteristics

38. European Medicines Agency (2008) Zoledronic acid. Summary of product characteristics

39. Rizos EC, Milionis HJ, Elisaf MS (2006) Fever with rash following zolendronic acid administration. Clin Exp Rheumatol 24:455

40. European Medicines Agency (2008) Strontium ranelate. Summary of product characteristics

41. Groves C (2008) Interstitial granulomatous reaction to strontium ranelate. Arch Dermatol 144:268-69

42. Boada A, Carrascosa J, Leal L, Ferrandiz C (2009) Generalized cutaneous drug eruption due to strontium ranelate. J Eur Acad Dermatol Venereol 0 (in press)

43. Pernicova I, Middleton ET, Aye M (2008) Rash, strontium ranelate and DRESS syndrome put into perspective. European Medicine Agency on the alert. Osteoporos Int 19:1811-12

44. Jonville-Bera AP, Crickx B, Aaron L, Hartingh I, utret-Leca E (2009) Strontium ranelate-induced DRESS syndrome: first two case reports. Allergy

45. Lee HY, Lie D, Lim KS, Thirumoorthy T, Pang SM (2009) Strontium ranelate-induced toxic epidermal necrolysis in a patient with post-menopausal osteoporosis. Osteoporos Int 20:161-62
46. Grosso A, Douglas I, Hingorani A, MacAllister R, Smeeth L (2008) Post-marketing assessment of the safety of strontium ranelate; a novel case-only approach to the early detection of adverse drug reactions. Br J Clin Pharmacol 66:689-94

47. European Medicines Agency (2008) Raloxifene. Summary of product characteristics

48. Layton D, Clarke A, Wilton LV, Shakir SA (2005) Safety profile of raloxifene as used in general practice in England: results of a prescription-event monitoring study. Osteoporos Int $16: 490-500$

49. European Medicines Agency (2008) Teriparatide. Summary of product characteristics

50. European Medicines Agency (2007) Parathyroid hormone. Summary of product characteristics

51. Burnett-Bowie SA (2008) Is twice-yearly denosumab beneficial in postmenopausal women with osteopenia but no history of fracture? Nat Clin Pract Endocrinol Metab 4:660-661

52. McClung MR, Lewiecki EM, Cohen SB, Bolognese MA, Woodson GC, Moffett AH, Peacock M, Miller PD, Lederman SN, Chesnut CH, Lain D, Kivitz AJ, Holloway DL, Zhang C, Peterson MC, Bekker PJ (2006) Denosumab in postmenopausal women with low bone mineral density. N Engl J Med 354:821-31

53. Center JR, Nguyen TV, Schneider D, Sambrook PN, Eisman JA (1999) Mortality after all major types of osteoporotic fracture in men and women: an observational study. Lancet 353:878-82

54. Bliuc D, Nguyen ND, Milch VE, Nguyen TV, Eisman JA, Center JR (2009) Mortality risk associated with low-trauma osteoporotic fracture and subsequent fracture in men and women. JAMA 301:513-21

55. Schnyder B, Pichler WJ (2009) Mechanisms of drug-induced allergy. Mayo Clin Proc 84:268-72 